\title{
Thirty-three years of progress: the International Workshops on Developmental Nephrology and the role of IPNA
}

\author{
Russell W. Chesney • Robert Chevalier
}

Received: 24 December 2013 / Revised: 24 December 2013 / Accepted: 30 December 2013 /Published online: 23 January 2014

(C) IPNA 2014

\section{Introduction}

The discipline of developmental nephrology represents the synthesis in the 1960s of advances in clinical and basic sciences. The clinical impetus was provided by the establishment of pediatric nephrology at this time, and the recognition that congenital anomalies of the kidneys and urinary tract comprise the leading causes of chronic kidney disease in children. Working together at Albert Einstein College of Medicine, Henry Barnett, Chester Edelmann, and Adrian Spitzer became leaders in exploring the unique anatomic and physiologic renal adaptations required by transition from fetal to postnatal life. They presented their findings at the first meetings of the International Congress of Nephrology in the 1960s, until the establishment of the International Pediatric Nephrology Association (IPNA) in 1974.

The International Workshops on Developmental Nephrology (IWDN) were established by Spitzer in New York City in 1980 and have been held every 3 years since. Thus, the 12th IWDN, held in Edinburgh, Scotland, occurred in the 33rd year of this series. Initially envisioned as a small meeting forum at which interested investigators could meet, exchange ideas, and critically evaluate recent work, its themes were renal embryogenesis, postnatal renal functional development, and renal metabolism. These workshops, initially called the International Workshops on Developmental Renal Physiology (IWDRP), are now firmly established as satellite

Dedicated to Adrian Spitzer

R. W. Chesney $(\bowtie)$

Department of Pediatrics, The University of Tennessee Health

Science Center, 50 N. Dunlap, Memphis, TN 38103, USA

e-mail: rchesney@uthsc.edu

R. Chevalier

The University of Virginia School of Medicine, Charlottesville, VA, USA meetings of IPNA and are held in the same year as the IPNA congresses [1]. Five of these meetings have been held in Europe, five in North America, and one each in Japan and Australia (Table 1).

The first meeting was held in New York in 1980 and was dedicated to Barnett in honor of his retirement. Its success led to the continuance of IWDN as satellite meetings of IPNA congresses. The second meeting, hosted in 1983 by Matthias Brandis, was held in Marburg and followed the pattern of a small, interactive meeting. The third IWDRP was held in Tokyo in 1986 and was hosted by Takeshi Hoshi. Michel Bergeron, a developmental renal physiologist, served as local host for the fourth meeting, held on an island on the St. Laurence River near Montreal. The fifth meeting was held on Lake Como, Italy, apart from the 1992 Jerusalem meeting of IPNA, and was led by Fabio Sereni. Airlie was the venue for the sixth meeting in 1995, with Robert Chevalier presiding; the IPNA congress was in Santiago, Chile. This meeting was the first to be referred to as the International Workshop on Developmental Nephrology (IWDN). Spitzer, a distinguished developmental renal physiologist, was an organizer of the first six workshops, and he established the precedent of stressing strong scholarship and inviting first-rank scientists to speak at plenary sessions.

The seventh workshop was held in Stockholm; the IPNA Congress was in London that year. For this 1998 meeting, the chairs were Anita Aperia and Gianni Celsi of Sweden. The eighth workshop, organized by Chevalier, Lisa Satlin, and Lisa Guay-Woodford, was held in Victoria, British Colombia, in 2001. Satlin chaired the ninth meeting in the Barossa Valley in 2004. In 2007, Endre Sulyak presided over the tenth meeting, in Pecs, along with Guay-Woodford. The 2010 IWDN was held in New Paltz, a bus ride up the Hudson River from the location of that year's IPNA Congress, and was organized by Norman Rosenblum and Jordan Kreidburg. The most recent meeting, held on Edinburgh University grounds in 
Table 1 Year and venue of International Workshops on Developmental Nephrology

\begin{tabular}{ll}
\hline Year & Location \\
\hline 1980 & New York City, New York, United States \\
1983 & Marburg, Germany \\
1986 & Tokyo, Japan \\
1989 & Montreal, Canada \\
1992 & Tremezzo, Italy \\
1995 & Airlie, Virginia, United States \\
1998 & Stockholm, Sweden \\
2001 & Victoria, British Columbia, Canada \\
2004 & Barossa Valley, South Australia, Australia \\
2007 & Pecs, Hungary \\
2010 & New Paltz, New York, United States \\
2013 & Edinburgh, Scotland \\
\hline
\end{tabular}

June 2013, was organized by Kriedburg and Carl Bates; the IPNA Congress was in Shanghai.

\section{Workshop format and themes}

Each workshop has followed the format of thematic sessions with plenary speakers, oral presentations, and separate poster sessions. Meetings have lasted for 2 to 3 days and generally have five to nine themes per workshop. The general overall theme has been that of the ontogeny of the kidney and lower urinary tract, but in general, each workshop has had its own theme or series of themes. The evolution of the science of kidney and upper and lower urinary tract development has guided the workshop organizers in planning these triennial meetings.

As Spitzer stated in the preface to the first workshop: "Those working in developmental renal physiology have now the ability to provide... information" about the "mechanisms behind various processes, knowledge regarding the emergence, and the maturation of these mechanisms becomes of paramount importance." He felt there was "more need than ever for opportunities to exchange experience and debate contradictory findings." He hoped that the workshop had served that purpose, and "also to establish a precedent to be followed" [2]. This precedent has clearly been firmly established, and this historical overview will examine how thinking in developmental nephrology has evolved over the past three decades.

From the beginning, the organizers of these workshops recognized that a dichotomy existed between pediatric nephrologists and other biomedical scholars who were active investigators in developmental nephrology. The pediatric nephrologist must have insight into the development, physiology, biochemistry, and embryogenesis of kidney and lower urinary tract development, as many patients for whom they care will have abnormalities of the urinary system, especially congenital anomalies of the kidney and urinary tract (CAKUT) [3]. At the same time, developmental biologists, geneticists, and adult nephrologists have interest in the developing kidney as a system of general biologic interest. From the first, scholars outside the field of pediatric nephrology have contributed immeasurably to the success of these workshops. The harmony between diverse scientists at these workshops has enhanced the content of the information presented and helped to advance knowledge in developmental nephrology.

\section{Review of each workshop}

The first workshop was titled "The Kidney During Development: Morphology and Function," and was held to honor Dr. Henry L. Barnett, one of the founding fathers of pediatric nephrology. Major themes were:

1. The development of renal histology and enzymology

2. The limit of size in the investigation of functional renal development

3. Developmental aspects of the process of glomerular filtration

4. Development of the renal prostaglandin system

5. Maturation of the urinary concentrating mechanism

6. The role of the kidney in electrolyte homeostasis during development

7. The development of the renal transport of organic molecules

Most invited speakers were pediatric nephrologists, but renal physiologists and biochemists made up a segment of the participants. This meeting set the pattern for future workshops and led to the publication of a book edited by Spitzer: The Kidney during Development: Morphology and Function [2].

The second IWDRP was held in Marburg and was organized by Brandis and Spitzer. Brandis was one of the organizers of the sixth IPNA Congress held in Hannover and hosted this workshop. An important theme was the physiology of kidney development and included topics such as the role of the kidney in phosphate homeostasis during growth, the effects of hypoxemia on renal function during maturation, and functional adaptation to reduced renal mass in early postnatal development. Again, renal physiologists and pediatric nephrologists were the principal speakers. In each of the first two workshops, studies in animals, especially dogs, rats, sheep (fetal), and guinea pigs, predominated. Some of the material presented at the workshop can be found in Paediatric Nephrology, edited by J. Brodehl and J.H.H. Ehrich [4]. Several distinguished German renal physiologists, 
including Rolf Kinne and Wilhelm Kriz, participated in the meeting.

The third IWDRP was held in Tokyo in 1986 and organized by Hoshi and Spitzer. Important themes were:

1. The development of the mesangium

2. Renal epithelial development as exposed by organotypic culture

3. Interrelationship between organelles in renal cells of the adult and developing rat; structure and function of outer vs. inner cortical tubules

4. Cell adhesion molecules, especially adhesins

5. The role of ion transport in cell proliferation

Original articles continued this theme of the power of cells in culture as a tool and examined factors such as epithelial growth factor and dopaminergic receptors. Brush border membrane vesicle studies were also presented for both phosphate and amino acid transport. A feature of this meeting was that a summary of this workshop was published in Pediatric Nephrology, the IPNA journal, which published summaries of many subsequent workshops [5].

The fourth IWDRP was held in Montreal and directed by Bergeron and Spitzer. This meeting continued the notion of the importance of extracellular signaling on growth factors in cells in culture and the importance of polypeptide growth factors in metamorphic differentiation. Molecular biologic tools were heavily emphasized, as was the cloning of genes, such as those for renin and angiotensin. This meeting marked a shift in emphasis away from developmental renal physiology to an analysis of developmental, vascular, and tubular biology. Special emphasis was placed on differentiation of various renal cells [6].

The fifth meeting was held in Tremezzo in 1992 and led by Spitzer and Sereni. Many new investigators in the field, including pediatric and adult nephrologists, physiologists, neonatologists, geneticists, developmental biologists, pathologists, and endocrinologists, attended. Common themes were:

1. The interaction of growth factors and the mechanisms of epithelial cells

2. The mechanisms of signal transduction

3. The regulation of gene expression

4. The isolation of ion and water channels

As Spitzer and Sereni noted: "The surge in interest generated by what is better described as developmental renal biology, rather than physiology, is likely explained by the realization that understanding of functional and structural phenomena requires knowledge of their emergence and subsequent change towards mature expression" [7].

The sixth IWDN, held in Airlie in 1995, was organized by Chevalier and Spitzer. The introductory remarks invited new scientists of renal development to contribute their work, and the workshop name was changed to developmental nephrology. Major themes explored were:

1. Early renal embryogenesis

2. Renal differentiation and commitment

3. Nephrogenesis: receptors, cell signaling, and cell effectors

4. Renal development, probed by vasoactive agents and growth factors

5. The pathophysiology of the developing kidney and urinary tract

Spitzer and Chevalier noted that the substitution of nephrology for physiology was not "cosmetic" but "reflected the profound revolution that occurred in our field due to the impact that cellular and molecular biology have on cell growth, differentiation and assembly"[8]. Whereas that workshop was held in the United States, the IPNA Congress was held in Santiago, Chile, South America.

The next workshop, the seventh IWDN, was held in Stockholm in 1998 and organized by Aperia and Celsi. The IPNA Congress was held in London that year. Predominant themes were:

1. Nephrogenesis

2. Angiogenesis

3. Regulatory systems

4. Molecular mechanisms of water and electrolyte handling

5. Apoptosis, a new theme referred to as a double-edged sword

This workshop was titled: "Early Renal Development: A Key to the Understanding of Adult Disease" [9].

The eighth IWDN, held in Victoria in 2001, was titled: "Genes, Morphogenesis and Function." The workshop organizers were Satlin, Guay-Woodford, and Chevalier. The themes included:

1. Molecular control of nephrogenesis

2. Nephron induction, patterning, and differentiation

3. Growth factors and receptors

4. Angiogenesis and vasculogenesis

5. Intrarenal hormones and development

6. Sorting and trafficking in epithelial development

7. Signaling and apoptosis

8. Developmental regulation of tubular transport

9. The role of aquaporins in the regulation of water metabolism [10]

This workshop preceded the IPNA Congress in Seattle, USA.

The ninth IWDN was held in the Barossa Valley in 2004 and was organized by Satlin. The first day focused upon 
molecular control of patterning in the kidney and gastrointestinal tract in health and disease. The importance of the number of nephrons at birth was stressed. The second part of the program focused upon patterning for nephron architecture at the level of the glomerulus and of both tubular and vascular structures. Processes involved in normal epithelial differentiation, including polarity and ontogeny of tubular transport, were explored. Finally, defects in terminal differentiation and response of the kidney to injury were major themes on the final day [11].

The tenth IWDN was held in 2007 in Pecs. It was organized by Guay-Woodford and Endre Sulyok and was titled: "Molecular Networks: Programming Normal Renal Development and Modeling Disease Patterns." It immediately preceded the 14th IPNA Congress in Budapest, Hungary. Four themes were explored:

1. Developmental nephrology

2. Branching morphogenesis

3. Cell biology of the developing upper and lower urinary tract

4. Genetic factors in renal and urinary tract development [12]

The 11th IWDN was held at Mohonk Mountain House, New Paltz, and was chaired by Rosenblum and Kreidburg. The theme of the workshop was "Genetic Programming and the Kidney: Progenitors Signaling and Morphogenesis in Health and Disease." The six subthemes of the meeting were as follows:

1. Stem cells, progenitors, and regeneration

2. Molecular mechanisms and patterning of the metanephric field

3. Morphogenesis of the renal collecting system
4. Signaling and control of nephron formation

5. Patterning and morphogenesis of the lower urinary tract

6. Molecular signaling and epithelial differentiation

Rosenblum noted that the "revolution" in biology continues. He further pointed out that "the synergistic tools of genetics and developmental biology are being used with increasing sophistication and specificity to identify the individual and combined contribution of genes that instruct the differentiation and morphogenesis of cells and cellular structures during renal morphogenesis." [13].

The most recent IWDN, the 12th, was themed: "From Basic Science to Therapeutics." It was held in Edinburgh in June 2013 and was led by Kreidburg and Bates. As in the 11th IWDN, there was a presentation of the Genitourinary Development Molecular Anatomy Project (GUDMAP), an atlas that combines information about specific gene knockout animals at daily stages of morphogenesis, as well as genegene interactions. GUDMAP, sponsored by the National Institute of Diabetes and Digestive and Kidney Diseases (NIDDK), is a consortium whose goal is to generate a detailed atlas of gene-expression patterns that drive kidney development. Session themes comprised:

1. Progenitors and stem cells: basic biology and therapeutic implications

2. Branching morphogenesis

3. Nephron number

4. Developmental physiology; congenital urologic malformations

5. Genetic diseases in pediatric nephrology

Also as in the 11th IWDN, there was information presented concerning gene silencing and the development and maldevelopment of the lower urinary tract. Another constant

Table 2 Evolution of developmental nephrology over 33 years as reflected by the 12 workshops

\begin{tabular}{lll}
\hline Year & Techniques, areas of study & Disciplines \\
\hline 1980 & Animal models (multiple species); in vitro nephron studies & Developmental anatomy, physiology, and biochemistry \\
1983 & & Cell and molecular biology \\
1986 & Cell and organ culture & \\
1989 & Gene cloning & \\
1992 & Vascular and epithelial cell biology & \\
$1995^{\text {a }}$ & Molecular embryology & Organ repair and regeneration \\
1998 & Mediators of cell survival and death & Developmental origins of health and disease (programming) \\
2001 & Gene expression and cell signaling in renal development & \\
2004 & Determination of nephron number, branching morphogenesis, response to injury & Genetics of renal development and maldevelopment \\
2007 & & Epigenetics in renal development and maldevelopment \\
2010 & Stem cells, progenitor cells; cell differentiation; & \\
2013 & GUDMAP (molecular anatomy of urinary tract) & \\
\hline
\end{tabular}

GUDMAP Genitourinary Development Molecular Anatomy Project

${ }^{a}$ Name changed from Developmental Renal Physiology to Developmental Nephrology 
feature at all 12 IWDN meetings over the 33 years of its existence is lively and interactive poster sessions.

\section{Workshop sponsors}

Sponsorship of the IWDN series has been primarily from three sources: the NIDDK, the March of Dimes, and IPNA. From the first workshop onward, a conference grant from the NIDDK has been pivotal in supporting the travel and registration of trainees and junior faculty members. Moreover, with the recent explosion of cell and molecular biology, as well as the molecular genetics of renal disease, this support has encouraged the participation of investigators from many disciplines to focus upon the developing kidney. Second, because congenital abnormalities of the kidney and urinary tract are often present at birth and result in a large fraction of cases of chronic kidney disease in children, the focused interest of the March of Dimes in genetic, congenital, and developmental disorders has led to their generous support. Finally, the IWDN became an official sponsored satellite meeting of all IPNA Congresses in 2007, but, indeed, the IPNA has supported all workshops since the first one in 1980.

\section{Conclusion}

In conclusion, a number of themes have been explored over the 33 years of the IWDN meetings (Table 2). Many species were explored in studies, including the chick, zebra fish, mouse, rat, guinea pig, dog, and human. Both transgenic and geneknockout animals have been used. Early meetings were centered on developmental renal physiology both in vivo and in vitro. Developmental renal biochemistry was examined, with an emphasis on cells in culture and organ explants. With the revolution in biology, analysis of development became the background of studies of vascular biology, differentiation of cells, and timing of the emergence of developmental genes. Knockout and transgenic species were used to perform informative genetic analyses of renal development. A major theme of the last six meetings has been an analysis of branching morphogenesis and the role of factors that influence it. The use of the GUDMAP consortium has permitted a more finely tuned insight into timing of expression of developmental genes and associated cofactors. The most recent major theme has been to examine progenitors of renal development and regeneration and the role of epigenetics in renal development. Throughout the more than three decades of these meetings and workshops has been the overriding concept of "all of the right things happening at the right time" (quotation from Jamie Davies in the Edinburgh opening session). Undoubtedly, new approaches to renal and lower urinary tract development will be established and will form the basis for themes at future workshops.
In the past 33 years, major advances in imaging of the urinary tract in utero as well as in the care of extremely lowbirth-weight preterm infants have contributed to the rapid growth of perinatology and neonatology. As a consequence, knowledge of normal and abnormal renal development has assumed even greater importance. The recognition by Barker and his associates of perinatal determinants (programming) of adult disorders has opened a new field of investigation: the "developmental origins of health and disease" [14]. Moreover, rapid advances in epigenetics have underscored the importance of environmental interactions with the genome in fetal and postnatal development [15]. These new areas of investigation will further expand the impact of developmental nephrology, extending connections with nephrologists to the adult population. The theme of the 2013 IWDN- "From Basic Science to Therapeutics"-clearly sets the stage for translation of discoveries into clinical practice and for many fruitful workshops to come.

\section{References}

1. Friedman A, Ehrich JHH, Chevalier R, Jones S (2010) A history of IPNA: from origins to 2010. http://www.ipna-online.org/wp-content/ uploads/2009/02/A-History-of-IPNA.pdf

2. The Kidney during Development (1980) Morphology and function. Masson Publishing USA Inc, New York

3. Renal Data System, 2013 USRDS Annual Data Report (2013) Atlas of Chronic Kidney Disease and End-stage Renal Disease in the United States. National institutes of Health, National Institute of Diabetes and Digestive and Kidney Diseases, Bethesda, MD http:// www.usrds.org/atlas.aspx

4. Paediatric Nephrology (1983) Proceedings of the 6th International Symposium of Paediatric Nephrology. Springer-Verlag, Berlin

5. Proceedings of the Third International Workshop on Developmental Renal Physiology (1988) September 6-7, 1986, Tokyo, Japan. Pediatr Nephrol 2:83-175

6. Proceedings of the Fourth International Workshop on Developmental Renal Physiology (1990) August 24-26, 1989, Montreal, Canada. Pediatr Nephrol 4:361-450

7. Proceedings of the 5th International Workshop on Developmental Renal Physiology (1993) Tremezzo, Italy, August 26-28, 1992. Pediatr Nephrol 7:597-697

8. 6th International Workshop on Developmental Nephrology (1996) Airlie, Virginia, USA, August 23-25, 1995. Pediatr Nephrol 10(818832):C173-C890, Proceedings and abstracts

9. Celsi G (2000) 7th International Workshop on Developmental Nephrology 9-11 September 1998, Stockholm, Sweden. Early renal development: a key to the understanding of adult diseases. Pediatr Nephrol 14:444-450

10. Satlin LM, Guay-Woodford L, Chevalier RL (2003) Proceedings of the Eighth International Workshop on Developmental Nephrology: genes, morphogenesis, and function. The sessions. Pediatr Nephrol 18:174-195

11. Satlin LM, 9th International Workshop on Developmental Nephrology (2004) http://search.engrant.com/project/3o1YVO/9th international_workshop_on_developmental_nephrology 
12. 10th International Developmental Nephrology Workshop (2007) Molecular networks: programming normal renal development and modeling disease pathogenesis

13. Rosenblum ND (2011) 11th International Workshop in Developmental Nephrology (IWDN). Pediatr Nephrol 26:13631364
14. Barker DJ, Bagby SP (2005) Developmental antecedents of cardiovascular disease: a historical perspective. J Am Soc Nephrol 16: $2537-2544$

15. O’Sullivan L, Combes AN, Moritz KM (2012) Epigenetics and developmental programming of adult onset diseases. Pediatr Nephrol 27:2175-2182 